\title{
DA TERRA PROMETIDA À TERRA DO ABANDONO: O LEGADO DO PROGRAMA DO BIODIESEL NO SERTÃO DO PIAUÍ
}

\author{
FROM THE LAND PROMISED TO THE LAND OF ABANDONMENT: THE \\ LEGACY OF THE BIODIESEL PROGRAM IN THE SERTÃO DO PIAUÍ
}

\author{
M. E. S., SILVA', \\ 1 Universidade Federal do Rio Grande do Sul, doutoranda do Programa de pós-graduação em \\ Sociologia.
}

\author{
ART I C LE INFO \\ Article history: \\ Received 2018-04-13 \\ Accepted 2018-04-30 \\ Available online 2018-05-02 \\ *Autor correspondente: \\ E-mail: elzasoarespi@gmail.com
}

\begin{abstract}
Palavras-chave:Reforma agrária. Biodiesel. Assentamento
\end{abstract} rural.

Keywords: Land Reform. Biodiesel. Rural Settlement.

RESUMO. A precariedade do acesso e permanência na terra é um problema agrário enraizado na estrutura social do Brasil, com expressividade, nas regiões com maiores desigualdades sociais no campo. E essa situação se agrava quando o Estado se propõe a solucionar o déficit da política de reforma agrária com programas que visam à inserção dos agricultores familiares pobres no mercado do biodiesel. O artigo em questão buscou analisar como o modelo de assentamento público-privado instalado no sul do Piauí no ano de 2005, contribuiu para atingir a dimensão social do Programa Nacional de Uso e Produção do Biodiesel - PNPB. Nessa experiência de assentamento, os agricultores foram assentados na condição de parceiros rurais da usina de biodiesel, tendo como promessa a doação da titularidade dos lotes da fazenda para aqueles que permanecessem produzindo oleaginosa para a empresa parceira por, no mínimo, dez anos. Metodologicamente, fez-se uso do método etnográfico, análise de diário de campo e entrevista semiestruturada com análise de conteúdo. Os resultados indicaram descompasso entre a lógica produtivista do modelo de assentamento com os modos de vidas dos agricultores parceiros, alterando, significativamente, suas relações com o trabalho, terra e moradia. Ademais, já se passaram dez anos e a promessa de doação dos lotes das terras para os agricultores não se cumpriu.

\begin{abstract}
The precariousness of access and permanence on land is an agrarian problem rooted in the social structure of Brazil, with expressiveness, in the regions with the greatest social inequalities in the countryside. And this situation is aggravated when the State proposes to solve the deficit of the policy of agrarian reform with programs that aim at the insertion of poor family farmers in the biodiesel market. The article in question sought to analyze how the public-private settlement model installed in the south of Piauí in the year 2005, contributed to reach the social dimension of the National Program of Biodiesel Use and Production - PNPB. In this settling experiment, farmers were settled as rural partners of the biodiesel plant, promising to donate ownership of the farm lots to those who had been producing oilseed for the partner company for at least ten years. Methodologically, we used the ethnographic method, field diary analysis and semi-structured interview with content analysis. The results indicated a mismatch between the productivist logic of the settlement model and the modes of lives of the partner farmers, significantly altering their relationships with work, land and housing. In addition, it has been ten years and the promise of donation of lots without burden to the State was not fulfilled.
\end{abstract}

\section{INTRODUÇÃO}


No Brasil, nas últimas três décadas registra-se a presença de inúmeras políticas públicas desenhadas e implementadas com foco na inserção dos agricultores familiares no mercado. Dentre essas, insere-se o Programa Nacional de Produção e Uso de Biodiesel (PNPB) que é uma política pública que busca a integração e o fortalecimento da agricultura familiar brasileira, tornando-a parte do processo produtivo do biodiesel. Como parte da estratégia de inserção da agricultura familiar na cadeia produtiva do biodiesel criou-se o instrumento legal - Selo Combustível Social - SCS - um programa de isenção fiscal concedido pelo Ministério do Desenvolvimento Agrário - MDA aos produtores de biodiesel que promoverem a inclusão social e o desenvolvimento regional, por meio da geração de emprego e renda para os agricultores enquadrados nos critérios do Programa Nacional de Fortalecimento da Agricultura Familiar - PRONAF (SILVA, et al, 2016).

$O$ desenho inicial do programa previa atingir 200 mil agricultores nos primeiros anos de implementação do programa, priorizando agricultores pobres das regiões menos desenvolvidas, com reconhecida concentração da pobreza rural' ${ }^{1}$. Diante desse desafio o MDA, Governo do Estado do Piauí e empresa produtora de biodiesel aliaram esforços numa parceria público-privada que resultou na construção do Núcleo de Produção Santa Clara - NPSC, um projeto piloto com viés de distribuição de terras e inclusão produtiva dos agricultores sem terras, considerada, uma importante estratégia para o alcance da meta social do programa do biodiesel.

Para viabilizar essa parceria, o Governo do estado do Piauí autorizou através do Instituto de Terras do Piauí - INTERPI a doação de 36 mil hectares para a empresa produtora de biodiesel construir a infraestrutura necessária para assentar 639 famílias de agricultores sem terras na condição de parceiros rurais da usina. Para se manterem nas terras do NPSC os agricultores precisavam disponibilizar a mão de obra existente no grupo familiar para cultivar mamona e atender à demanda da usina de biodiesel da empresa parceira. Essa modalidade de assentamento em terras públicas, utilizando-se de recursos financeiros da iniciativa privada, foi denominada pela Lei estadual n. $=$ 5.333/2003 de "reforma agrária privada". Através dessa lei o Estado autorizou a empresa produtora de biodiesel, após uma década de exploração comercial das terras do NPSC a doar lotes de 25 hectares para aquelas famílias que permanecessem na parceria de produção, por no mínimo, dez anos.

A promessa de doação das terras ao término do contrato de parceria foi um dos motivos que despertou o interesse de centenas de agricultores que viviam na condição de meeiros, arrendatários, moradores, sitiantes, caseiros e outras formas de sujeição na relação com a terra, trabalho e moradia. Essas famílias, oriundas de diversas origens geográficas, vislumbraram nesse deslocamento a oportunidade de acesso à moradia, terra e condições para reprodução social do seu grupo familiar. Para melhor compreensão, o artigo está estruturado em três partes, além desta introdução e da conclusão. Na primeira parte, apresentarei as expectativas iniciais do PNPB sobre a inclusão da agricultura familiar na cadeia produtiva do biodiesel como estratégia de geração de renda e acesso a terras para agricultores pobres do Piauí, contextualizando de forma genérica 0 debate sobre a singularidade de um assentamento que não está em consonância com o que, conceitualmente, se reconhece por Projetos de Assentamentos Rurais no Brasil. Na segunda parte, abordarei os conflitos

${ }^{1}$ Para o PNPB o critério de pobreza e extrema pobreza é o mesmo adotado pelo Governo Federal no ano 2003 para definir quem seriam os beneficiários do Programa Bolsa Família - PBF (BRASIL, 2005). Em junho de 2011 através do Programa Brasil Sem Miséria os valores foram ajustados através do Decreto Presidencial n 7.492 , de 2 de junho de 2011. 
que surgiram pela imposição de novas práticas de cultivos e modelo de moradias circulares implementadas com vistas a controlar as práticas e modos de vidas dos agricultores parceiros. $\mathrm{Na}$ terceira parte, tratar-se-á dos desafios de adaptação ao modelo de produção focada no agronegócio dos biocombustíveis e, por fim, as conclusões com os principais pontos de conflitos sociais e estratégias de sobrevivência que emergiram dessa proposta de desenvolvimento rural, distribuição de terras e acesso ao mercado dos biocombustíveis pela agricultura de base familiar.

\section{MÉTODO}

A abordagem teórico-metodológico para esse trabalho está fundamentada na pesquisa qualitativa com 0 uso do método etnográfico, técnicas de diário de campo e entrevista semiestruturada com análise de conteúdo. Os dados apresentados são resultados da pesquisa de mestrado 2 que ocorreu no ano de 2010, período esse, marcado por conflitos gerados pelos desencontros das expectativas dos agricultores e da agroindústria do biodiesel. Em janeiro do ano 2018 alguns dados foram atualizados durante pesquisa de campo para a tese de doutoramento. $O$ campo revisitando possibilitou-me estabelecer conexões sociológicas entre as expectativas de aquisição dos lotes do NPSC e realidade vivenciada atualmente.

A etnografia aconteceu por um período de cinco meses, ininterrupto, no qual a pesquisadora morou na residência de cinco famílias que tiveram suas trajetórias sociais etnografadas, participando das atividades cotidianas, como trabalho na roça, colheita, atividades domésticas, festividades, dentre outras práticas sociais como fofocas e intrigas familiares (COMEFORD, 2003) e, em algumas vezes, apaziguadora de conflitos coletivos. Os dados provenientes da observação participante (GOLDENBERG, 2004) foram registrados em diários de campo (BRANDÃO, 1982), articulando-as com entrevistas semi-estruturadas (GASKELL, 2002), registros fotográficos e elaboração de mapas etnográficos.

$\mathrm{Na}$ atualização dos dados, aqui denominada de campo revisitado ${ }^{3}$ a pesquisadora retornou ao NPSC para entrevistar dois extensionistas rurais e uma liderança da FETAG/PI que contribuíram com a implementação do programa do biodiesel no Piauí. Foi nessa reaproximação com os agricultores que permaneceram no NPSC que surgiu a ideia de atualizar os dados da pesquisa realizada em 2010. Para tal atualização, adotou-se entrevistas semiestruturadas com o uso de gravador de entrevistas com quatro informantes e observação participante em duas células de produção que estão situadas em áreas mais isoladas do NPSC. Revisitar o campo significou, também, uma espécie de rompimento epistemológico com conhecimentos apreendidos anteriormente, resultado dessas relações de proximidades construídas durante a etnografia.

\section{O PROGRAMA DO BIODIESEL: UMA ESTRATÉGIA DE INCLUSÃO DA AGRICULTURA FAMILIAR NO SEMIÁRIDO DO PIAUÍ?}

A regulamentação do PNPB no ano de 2004 representou um marco nas políticas de produção de biocombustíveis no Brasil, uma vez que a formulação desta previa a importante participação de um segmento da agricultura, negligenciada, na maioria das vezes, pelas políticas públicas agrícolas.

\footnotetext{
Dissertação de mestrado intitulada "Etnografia da terra prometida: trajetórias sociais, conflitos e cotidiano dos/as camponeses/as parceiros/as da Brasil Ecodiesel - O caso da Fazenda Santa Clara, no Piauí”, defendida em 2011, pelo Programa de Pós-Graduação em Antropologia da Universidade Federal do Piauí.

${ }^{3}$ Pesquisa de doutorado, em andamento, com a orientação da professora Dr. Marília Patta Ramos, pelo Programa de PósGraduação em Sociologia da UFRGFS.
} 
Para alcançar a meta de inclusão social o programa criou o Selo Combustível Social, uma estratégia de aproximação dos agricultores familiares com as empresas produtoras do biodiesel. A meta inicial era inserir 200 mil agricultores nos primeiros anos de implementação do programa, priorizando assim, a região norte e nordeste do Brasil. Como no nordeste alguns estados, a exemplo, da Bahia e Ceará, os agricultores já possuíam experiências com o cultivo da mamona, essa cultura torna-se a eleita como principal oleaginosa para a região. Entretanto, na prática, o biodiesel extraído da mamona apresenta-se como inviável por tratar-se cultura de sequeiro o que, certamente, anula a possibilidade de escala de produção, elemento fundamental para assegurar o funcionamento das usinas de biodesel.

O processo de inclusão dos agricultores familiares no PNPB ocorre a partir da concessão do SCS a empresas produtoras do biodiesel que passam a comprar matéria prima dos agricultores que aderiram ao programa e, em alguns estados, pela instalação dos Projetos Polos de Produção de Biodiesel. Entretanto, quem usufrui dos benefícios do SCS são as usinas produtoras de biodiesel. A estas são concedidos benefícios fiscais, como isenção das alíquotas de PIS/PASEP e COFINS, com coeficientes de redução diferenciados para o biodiesel, variando de acordo com a matéria-prima e região da aquisição ${ }^{4}$; reserva de mercado de $80 \%$ do volume de biodiesel comercializado através dos leilões da ANP5; acesso a melhores condições de financiamento no BNDES, Banco da Amazônia (BASA), Banco do Nordeste (BNB) e Banco do Brasil, entre outros benefícios (BRASIL, 2005).

Assim, o biodiesel tornou-se um nicho de mercado interessante para a indústria dos biocombustíveis e despertou o interesse de investidores privados, sobretudo pelas facilidades de participação em leilões e outros benefícios que só seriam possíveis pela conquista do Selo Combustível Social. De acordo com a Agência Nacional de Petróleo e Biocombustíveis - ANP (2017), no Brasil existem 61 empresas produtoras de biodiesel, sendo que 41 delas já possuem o Selo Combustível Social (BRASIL, 2015) e as demais estão com a documentação em fase de análise para receberem a concessão de uso do SCS. Isso posto, fica evidente que as usinas buscam conquistar do SCS como estratégia de acesso facilitado ao mercado do biodiesel. E, nesse sentido, a participação dos agricultores familiares serve como estratégia de legitimação dos benefícios usufruídos pelas usinas que receberam SCS.

Os agricultores que assinaram contrato de parceria com a empresa de produção de biodiesel nos momentos de enfrentamento ao modelo de produção exclusiva para o mercado do biodiesel questionavam os benefícios usufruídos pelas empresas, enquanto que, aos agricultores parceiros, cabia a árdua responsabilidade de fornecer matéria prima na modalidade de contratos antecipados, proibidos de cultivar outras culturas alimentares, sujeitando-se às normas do agronegócio. A força da estrutura do agronegócio que imperava no NPSC submetia os agricultores "à lógica de reprodução da força de trabalho expressa pelas condições de exploração e de classe" (BRAGA; FIUZA; REMOALDO, 2017, p. 372).

Nesse contexto, é importante considerar que mesmo o SCS sendo concedido e fiscalizado pelo extinto Ministério do Desenvolvimento Agrário - MDA os seus dirigentes não conseguiram impedir o avanço do monopólio da soja em detrimento de outras oleaginosas previstas para serem

\footnotetext{
${ }^{4}$ Ver Decreto № 5.297, de 6 de dezembro de 2004; Decreto № 6.458, de 14 de maio de 2008 e Decreto № 6.606 , de 21 de outubro de 2008

${ }^{5}$ Ver Resolução № 5, do CNPE, de 3 de outubro de 2007.
} 
inseridas na matriz energética do Brasil, conforme desenho inicial do programa. Nos últimos dez anos - SCS passou por várias alterações que distanciaram cada vez mais os agricultores familiares da dimensão social do PNPB, transformando-o num programa de monocultivos, com centralização regional, com flexibilização das regras do SCS para atender às constantes pressões das entidades representantes dos produtores de biodiesel, estes, contrários à participação autônoma dos agricultores de base familiar na cadeia produtiva do biodiesel. Destaca-se que $90 \%$ dos agricultores que continuam fornecendo matéria prima para o PNPB estão localizados na região sudeste do Brasil, com expressividade, para o estado do Rio Grande do Sul, o que explica a predominância da soja com 99\% de participação na matéria prima utilizada na produção de biodiesel (SEAF, 2017).

A experiência vivenciada pelos agricultores no sertão do Piauí foi caracterizada pela subordinação do agricultor parceiro às regas da indústria do biodiesel. Como exemplo, podemos citar que o modelo de Assistência Técnica e Extensão Rural - Ater adotado pela usina era excludente e vertical. Os agricultores eram cobrados por escala de produção baseada em um calendário agrícola que não valorizava os conhecimentos e experiências dos agricultores parceiros. Contudo, esses de agricultores não se adaptaram ao modelo de Ater e, aos poucos, foram subvertendo as regras do modelo calendário agrícola com a introdução de cultivos para o autoconsumo, sobretudo, a partir da seca prolongada no ano de 2010. Muitos agricultores no Piauí abandonaram a produção de mamona porque o custo da alimentação subiu e eles precisavam plantar seu próprio alimento, já que com a venda da pouca mamona tornava-se inviável.

Outro aspecto de destaque para a não inclusão social da agricultura familiar no Piauí está ligado aos sucessivos aumentos dos percentuais da mistura obrigatória do biodiesel ao óleo diesel. Um programa que exige um volume extraordinário de matéria prima não está pensando em inclusão de agricultores que produzem mamona colhendo à mão, fazendo os tratos culturas de hectares acima da capacidade de mão de obra disponível na família e no final ainda colher apenas 250 ou 450 quilos conforme registrado nas safras de 2009/2010. O Governo aumentava a demanda por biodiesel, provocado pelo setor empresarial e as usinas parceiras precisavam acelerar a produção de matéria prima pressionando os agricultores parceiros, em outras palavras, o programa de inclusão social do PNPB é regido pelas regras do mercado do agronegócio.

À luz destas dessas constatações é possível inferir que a parceria rural que se desenhou no NPSC com perspectivas de distribuição de terras e inserção comercial na cadeia produtiva do biodiesel, está aquém da situação clássica estudada por Antônio Cândido (1987) no livro "Os parceiros do Rio Bonito". No clássico estudo, o autor apresenta uma parceria de arrendamento, unindo parceiros e proprietários, num universo social em que as distâncias sociais e as distorções na gestão dos negócios são relativamente pequenas. Enquanto que, na experiência estudada no NPSC a parceria entre os agricultores e a usina do biodiesel foi fortemente marcada por relações assimétricas de poder, provocadas pela incompatibilidade de interesses: de um lado, a usina demandava escalas de produção acima da capacidade de mão de obra disponível nas famílias parceiras, e do outro, agricultores resistindo às constantes cobranças dos extensionistas rurais para colocarem em prática um calendário agrícola voltado, exclusivamente, para o mercado. Os investidores dos agrocombustíveis esperavam que os agricultores do NPSC se tornassem os responsáveis pelo abastecimento das refinarias do grupo, o que, na prática, não aconteceu, vindo inclusive a comprometer o funcionamento do Pólo de esmagamento instalado no município de 
Floriano no estado do Piauí por ausência de matéria prima. Quando isso não acontece a empresa deixa de ver o NPSC como empreendimento e dar início a sua saída decretando falência no ano de 2012 deixando os agricultores desassistidos e com sérias dificuldades de se manterem numa área de grandes proporções territoriais.

A empresa parceira abandonou os agricultores sem realizar o processo de distribuição dos lotes de 25 hectares para as famílias conforme previsto em contrato. Em 2018 a situação vivenciada pelos agricultores é de total abandono. Os agricultores estão organizados em associação, criada recentemente com o intuito de provocar o Estado para a regularização fundiária das terras do NPSC.

O legado do programa do biodiesel no NPSC é de devastação. Os espaços físicos construídos para uso coletivo estão se deteriorando por falta de manutenção. Dentre esses espaços, a escola de ensino infantil não possui água para o desenvolvimento das atividades escolares e nem para o consumo humano, parte do teto da escola e do posto de saúde desabaram, a escola de ensino médio foi desativa pelo Estado no ano de 2015, deixando centenas de jovens fora da sala de aula, as bombas dos poços artesianos que abastecem as residências nas células estão queimadas, obrigando as famílias a comprarem água potável, no período chuvoso, parte das famílias que moram nas células mais distantes da $\mathrm{Pl}-141^{6}$ ficam isoladas pelas péssimas condições de acesso das estradas vicinais que ligam uma célula. No aspecto produtivo, os agricultores não conseguem acesso a crédito porque não possuem documentos que atestem sua atual relação com as terras do NPSC, mas, ainda assim, estão cultivando nos pequenos lotes que ficam próximos das suas residências.

No quesito inclusão da agricultura familiar na cadeia produtiva do biodiesel o estudo de Silva et al. (2016) constatou que a construção social do programa do biodiesel foi permeada por uma lógica produtiva, com limitada valorização do conhecimento e experiências dos agricultores familiares, seus recursos naturais, dimensão tecnológica, organizacional, sociopolítica e cultural.O não reconhecimento das particularidades inerentes e esse grupo social acarretou na não inclusão social dos agricultores do NPSC na cadeia produtiva do biodiesel.

\section{CASA-ROÇADO: CONFLITOS ENTRE O ESPAÇO CONCEBIDO PELO NPSC E O ESPAÇO VIVIDO PELOS PARCEIROS RURAIS}

A moradia para os camponeses tem vários sentidos e múltiplos significados. Casa e o roçado estão imbricados numa dinâmica espacial que se funde enquanto espaço para viver, conviver, plantar, colher e comer (BRANDÃO, 1981). A partir da perspectiva de sentidos e significados, o modelo de moradia adotado no NPSC enfrentou resistências por parte das famílias que se recusavam a viverem em espaços que dificultavam as diferentes práticas cotidianas, trabalho, vida familiar e consumo dos sujeitos individuais e coletivos dentro de uma proposta de viverem em espaços controlados pela empresa.

Ao chegarem ao assentamento no NPSC às famílias foram distribuídas em espaços denominados por células de produção. Essas células foram construídas com propósito de dupla utilidade: moradia e produção. Conforme mapa etnográfico (fig.1) cada célula possui 35 casas dispostas em formato circular, uma caixa d'água, poço artesiano, um campo de futebol, improvisado pelos jovens dessa célula etnografadas e um galpão central para as práticas coletivas do grupo,

\footnotetext{
${ }^{6}$ Rodovia que dá acesso aos municípios do Sul do Piauí e transnordestina.
} 
Figura 1: Mapa etnográfico de uma célula de produção e moradia

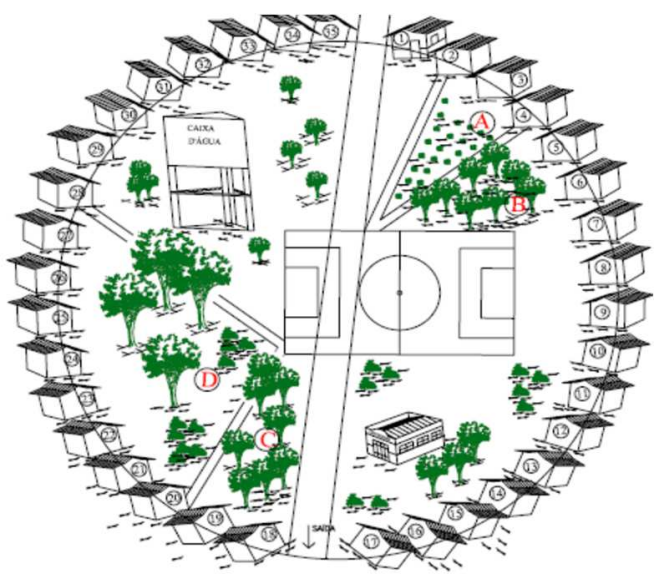

Fonte: elaboração própria, 2010.

Adaptar-se ao novo formato da moradia foi o primeiro desafio enfrentado pelas famílias, uma vez que, este modelo possibilitava que todas as casas fossem, simultaneamente, visualizadas, favorecendo assim, o controle do dos agricultores, conforme narrativa:

Duas vezes por dia os técnicos da empresa vinham olhar se a gente estava na roça ou dentro de casa. Mas, a gente também enganava eles, muitas das vezes a gente saia de casa, fechava as portas, mas a gente estava na mata, e, não cuidando da roça de mamona. Eles [empresa] fizeram essas casas assim, foi de propósito para vigiar o povo (Parceiro rural, 47 anos).

Uma cláusula no contrato de parceria proibia qualquer alteração na estrutura física das casas (individualmente) e nas células (coletivamente). Os agricultores parceiros estavam proibidos de plantar quaisquer árvores no centro das células ou na frente das casas de modo que impedissem a visualização, simultânea, de todas as casas pelos extensionistas rurais. Todavia, a partir do ano de 2008 os agricultores subverteram essas regras na busca pela autonomia perdida nesse novo espaço de moradia. Estes plantaram pés de caju, de ipês, de manga, ou seja, árvores de grande porte no centro da célula na tentativa de impedir o olhar atento e fiscalizador da empresa sobre o que estavam fazendo em suas casas. Quando os extensionistas chegavam às células ordenavam que retirassem aquelas plantas argumentando que a área estava com aspecto de área abandonada. Essa proibição, expressa em contrato, representava para a empresa a manutenção da sua autoridade sobre as famílias e a sua violação ameaçava a sustentabilidade produtiva do NPSC.

As constantes tentativas de interferências no desenho original das moradias por parte dos agricultores pode ser analisada pelo que Scott (2002) denominou por "formas cotidianas de resistências". A partir dessa perspectiva teórica foi possível apreender que as resistências que emergiram entre os anos de 2005/2012, fossem elas coletivas ou individuais, eram, particularmente, importantes no enfrentamento do poder de mando da empresa e, para o processo de retomada da relativa autonomia perdida nos espaços de moradia.

Ainda sobre a construção de espaços físicos com intuito de controlar o comportamento dos agricultores, através da vigilância constante e da punição dos que subvertiam as regras da empresa, passamos a analisar essa experiência a partir da contribuição teórica de Foucault (1978), que ao 
estudar a sociedade disciplinar, constatou que a sua singularidade reside na existência do desvio diante da norma. E assim, para "normalizar" o sujeito moderno, foram desenvolvidos mecanismos e dispositivos de vigilância, capazes de interiorizar a culpa e causar remorsos pelos seus atos. Se pensarmos as células de produção como modelo arquitetônico que permitia ver sem ser visto, como, por exemplo, o panóptico estudado por Foucault (1978) é possível que estejamos tratando de um modelo de cunho coercitivo e disciplinatório que almejava, acima de tudo, o controle social dos agricultores parceiros para se tornarem obedientes ao modelo de produção capitalista. $O$ que, na prática, não aconteceu.

Quando entrevistado, o idealizador do projeto de moradia para o NPSC afirmou desconhecer qualquer semelhança ou inspiração no panóptico Bentham e que, o modelo de arquitetura não foi intencional, mas que, na prática, terminou facilitando o trabalho dos extensionistas que, numa única visita, conseguiam visualizar todas as casas ao mesmo tempo. As palavras do empresário confirmam os questionamentos dos agricultores parceiros sobre a sensação de constante vigilância sobre eles.

As coerções físicas sofridas pelos agricultores que, isoladamente, iam alterando os formatos das suas casas, despertaram no grupo o sentimento de comunidade ${ }^{7}$, sobretudo, entre aqueles que compartilhavam da mesma origem geográfica. Depois do registro de violência física contra uma família que havia alterado um cômodo da casa, os agricultores se articularam coletivamente e mudaram a cor das casas, plantaram árvores, construíram bares, mercadinhos, igrejas, clubes todos em comum acordo para se protegerem mutuamente. De tal modo, partiram do entendimento de que a empresa não conseguiria controlar a ação coletiva. E, de fato, a empresa não conseguiu controlar esse movimento silencioso que ocorreu nas dezoito células de produção. As células (moradias) como preferem chamar atualmente, estão modificadas, todas com características peculiares às posses do "proprietário".

O sentimento de comunidade foi fundamental para a contraposição ao modelo de casaroçado vigiado. As ações de contestação às normas vigentes passaram do individual para o coletivo, conforme narrativa abaixo:

Chegamos à conclusão de que todos estavam aqui [Fazenda Santa Clara] para ter direito a um pedaço de terra. $\mathrm{E}$ todo mundo estava sofrendo porque não podia nem mandar na própria casa e tendo que ser vigiado. Ai, não tem outro jeito de enfrentar a situação que não seja unir e fazer tudo no acordo [com outros agricultores]. Assim, fica mais difícil de expulsar todo mundo por desobediência. Se um pintava a casa, todo mundo que podia pintava. Se um plantava pé de caju na frente da casa, todo mundo plantava. Chegou um momento que a empresa se convenceu que não podia com nós. $E$ fechava os olhos para as mudanças. E assim, fomos tomando o nosso poder de donos das nossas casas e roçadinhos (Agricultor parceiro, 52 anos).

Nessa perspectiva, é possível inferirmos que o poder do subalterno (SCOTT, 2000) dos agricultores nessa luta prosaica, mas constante, contribuiu para que a empresa parceira recuasse, revendo seu modelo de gestão, que até então se baseava no controle, sujeição e punição dos agricultores parceiros que subvertiam suas ordens no âmbito da casa-roçado.

7 Comunidade refere-se a uma coletividade na qual os participantes possuem interesses comuns e estão afetivamente identificados uns com os outros (Durham, 2004) 
Não podemos perder de vista que a moradia, no contexto analisado, representava para esses agricultores, o único espaço em que poderiam, ainda, exercer sua autoridade de provedor da família frente às constantes mudanças e sensação de insegurança, que permeavam as relações de trabalho e moradia nesse novo espaço.

No campo revisitado, observou-se que os agricultores, mesmo sem receberem o título de propriedade dos lotes que inclui a casa de moradia, continuam fazendo as reformas necessárias tais como: ampliação dos cômodos de acordo com a necessidade da família, pinturas, arborização, mercearias, barbearias, dentre outras construções que permitam a reorganização espacial e a reprodução social do grupo familiar. As casas continuam na disposição circular, entretanto, as mudanças acima mencionadas, possibilitaram a esses "sujeitos sociais construírem o cenário entre a natura e a cultura, sendo esse processo expresso pelos seus modos de vida" (BRAGA; FIUZA; REMOALDO, 2017, p. 372 - 373). Ao retomarem o controle do espaço concebido pelos princípios do agronegócio dos biocombustíveis os agricultores parceiros reforçaram nessa retomada o constructo dos seus modos de vidas, tais como normas, hábitos e valores.

\section{NPSC E O FRACASSO ANUNCIADO DE UM MODELO DE PRODUÇÃO FAMILIAR EXCLUSIVA PARA O MERCADO DO BIODIESEL}

O contexto social dos agricultores assentados na condição de parceiros rurais no NPSC se aproxima do conceito de "condição camponesa" cunhado por Ploeg (2016). São agricultores com trajetórias de vidas marcadas pela submissão, dependência, privação e ameaça com a deterioração de seus meios de vida. Para o autor, as funções sociais e produtivas que regem o funcionamento de uma unidade de produção camponesa e de uma fazenda capitalista são relativas (PLOEG, 2016). No caso do NPSC, por exemplo, a escala de produção para a empresa parceira representava a sua permanência no mercado do biodiesel, enquanto que, para os agricultores parceiros, representava o rompimento com suas práticas de cultivos alimentares para o autoconsumo. Corroborando com essa ideia Chayanov (1966 apud PLOEG, 2016, p. 41) entende que "o coração pulsante de toda unidade de produção camponesa é o equilíbrio trabalho consumo, isto é, relação entre as demandas de consumo da família e a força de trabalho disponível dentro da mesma família".

O modelo de produção adotado pela usina do biodiesel não contemplava a necessidade de produção para o autoconsumo demandada pelas famílias parceiras. E, nesse sentido, para viabilizar a produção da oleaginosa em escala comercial a empresa absorvia toda a mão de obra disponível na família, gerando o que Ploeg (2016) denominou por desequilíbrio entre a utilidade e penosidade do trabalho desses agricultores. Para o autor a utilidade é o oposto da penosidade - os benefícios extras, ou seja, na medida em que o agricultor aumenta a produção, diminui a utilidade. E a agricultura camponesa busca o equilíbrio entre ambas, ou seja, uma lógica de produção que esteja na dinâmica da utilidade (PLOEG, 2016)

A teoria das estratégias de resistências cotidianas cunhada por Scott (2000) lançou luzes na compreensão de um movimento silencioso que ocorria entre os agricultores como tentativa de romper com o modelo de produção voltado exclusivamente para o mercado, cuja estratégia da empresa era proibir os agricultores parceiros de cultivar outros cultivos que não fosse oleaginosa para a produção do biodiesel. Como enfretamento a essas proibições, os agricultores iam abandonando aos poucos os tratos culturais dos lotes da empresa para produzir alimentos culturas para o autoconsumo. 
Outro aspecto a se considerar no contexto da produção comercial, diz respeito ao modus operandi dos agricultores em relação à capacidade laboral na terra, conforme relato:

Essa gente toda que veio para cá [Fazenda Santa Clara], inclusive nossa família, estava acostumada a trabalhar em terra pouca [...] área que chegava a quatro tarefas ${ }^{8}$, no máximo. Ai, da noite pro dia a gente se pega na obrigação de cuidar de lotes com doze tarefas. Muitas famílias abandonaram os lotes do patrão [empresa parceira]. A gente fingia que ia para a roça e ficava era escondido dentro de casa (Agricultor parceiro, 49 anos).

Os agricultores, por diversas vezes, reivindicaram redução do tamanho dos lotes de produção da mamona porque não conseguiam realizar os tratos culturais demandado pelo referido cultivo, mas a empresa se mantinha firme no propósito de produzir tal oleaginosa para abastecer as suas usinas. Não visualizando possibilidade de redução dos lotes, os parceiros rurais passaram a boicotar ${ }^{9}$ a produção da mamona. Por boicote, nesse contexto, entende-se $o$ ato de abandonar os tratos culturais da mamona, simulando a ida para os lotes e ficando em casa escondidos até o horário estabelecido para estarem na roça.

Salientamos que a mamona é uma cultura marcada por processos manuais. Isso significa dizer que, para atender a lógica de produção em escala comercial no NPSC a empresa dependia, exclusivamente, da mão de obra dos agricultores parceiros. O que, certamente, não restava tempo para as famílias se dedicarem a produção dos roçados com vistas ao autoconsumo.

Aos assinarem o contrato de pareceria os agricultores tinham que concordar com o modelo de produção adotado pela empresa, cujo trabalho familiar era a contrapartida para assegurar o direito á titularidade dos lotes do NPSC ao término do contrato de parceria. Mesmo assinando o contrato, os agricultores resistiram ao modelo de calendário agrícola baseado na lógica produtivista e mercantil capitalista (PLOEG, 2016). E como consequência dessas resistências, a empresa registrava quedas bruscas na produção da mamona em decorrência do abandono dos lotes pelas famílias que passaram a se dedicarem aos roçados para o autoconsumo, mesmo, sem a autorização da empresa.

Quando a empresa tomou conhecimento de que os agricultores estavam cultivando roçados clandestinos nas terras do NPSC, redefiniram o calendário agrícola, introduzindo o cultivo de mandioca e feijão na condição de meeiros. Como as terras, juridicamente, pertenciam à empresa por um período de dez anos, cabia a esta, o direito de exploração comercial e, conseqüentemente, de exploração da mão de obra dos agricultores parceiros. Entretanto, a relação de meeiros, também, não foi pacifica. Centenas de famílias decidiram por não entregarem a parte da produção que, supostamente, cabia à empresa.

O fracasso na integração da agricultura de base familiar à agroindústria do biodiesel se deu a partir de um conjunto de fatores, sendo eles: dificuldade para adaptação à produção de mamona, abandono das práticas produtivas vivenciadas antes de irem para o assentamento, e a proibição da criação de pequenos animais nos lotes e dos roçados para o autoconsumo. Ademais, todas essas questões terminaram acirrando disputas de poder entre os parceiros rurais e os representantes da empresa. Assim, os conflitos gerados pela adaptação e (re) significação das "novas" práticas sociais e culturais por parte desses agricultores transformaram o NPSC num espaço de constantes tensões por

\footnotetext{
${ }^{8}$ Uma tarefa no Piauí equivale a 0,36 hectares.

${ }^{9}$ Termo utilizado nas recorrentes falas dos agricultores entrevistados.
} 
estarem submetidos a constantes pressões para produzirem dentro das metas estabelecidas pela empresa e sob fiscalização quanto aos horários em que deveriam estar nos lotes cultivando a mamona.

Outra questão importante a ser considerada é que, quando se trata dos saberes e experiências acumuladas pelos camponeses, Suarez (1983) entende que o campesinato desenvolve um conhecimento, ou saber, que lhe é próprio, o que leva a pensar que sua reprodução depende desse saber, tanto quanto das relações de produção que se estabelecem. A reprodução dessas relações de produção depende da operacionalização do saber que rege o processo de trabalho, ao mesmo tempo em que são elas próprias a condição para essa operacionalização. Dessa forma, a mamona enquanto principal cultivo passou a ser vista pelos agricultores como o símbolo do rompimento com os seus modos de vida anteriores. Para Scott (2002), naquelas experiências cujos camponeses se encontram em uma situação-limite de controle, as estratégias na busca de espaços de autonomia nos processos produtivos tornam-se uma constante no cotidiano das famílias.

Corroborando com o debate sobre políticas públicas voltadas para a agricultura, Suarez (1983) afirma que no Brasil, na maioria das vezes, essas políticas marginalizam a economia camponesa com redução da aplicação do conhecimento tradicional na roça, em especial aquele direcionado para a produção de alimentos, o qual os agricultores estavam habituados a praticar. A autora demonstra que experiências de desenvolvimento da agroindústria com a valorização das terras, dentre outras questões relevantes, provocam mudanças no tradicional processo de trabalho, orientado por um conhecimento camponês (SUAREZ, 1983).

Todavia, o processo de modernização ou adaptação às mudanças implica na aquisição, por parte dos agricultores, de outro saber, mesmo reconhecendo que são portadores de um saber próprio, saber este que não apenas orienta a prática rotineira, mas que contém elementos capazes de neutralizar pressões externas, dissolutivas, de incorporar a inovação e de se atualizar face à mudança (SUAREZ, 1983).

Apesar da retomada da autonomia perdida durante os anos de parceria rural, os agricultores familiares que continuam, atualmente, no NPSC estão aos poucos retomando os cultivos nos seus roçados, com as dificuldades mencionadas no tópico anterior. A organização da produção está voltada para o autoconsumo e, a parte excedente é destinada a comercialização nas feiras livres dos municípios vizinhos. As famílias estão se dedicando aos cultivos de sequeiro com destaque para o milho, feijão e mandioca. Em nos favoráveis à produção de caju, as famílias se dedicam a colheita dos frutos para venda in natura do pseudofruto e fruto (castanha) do caju, sendo esta, uma importante fonte de renda no período de entressafra. A criação de pequenos animais (aves caipiras, suínos e caprinos) é uma atividade que vem sendo retomada aos poucos. As famílias não conseguem acessar créditos destinados a aquisição das matrizes melhoradas porque não possuem qualquer documento que comprove sua relação com as terras do NPSC. Entretanto, a criação de animais, daqueles que já iniciaram a atividade, encontra-se comprometida por falta de água. Observou-se também, que a prática da migração temporária do chefe da família para as colheitas em outras regiões do Brasil voltou a fazer parte da composição da renda familiar.

Por fim, no NPSC a proposta de inclusão produtiva dos agricultores familiares na cadeia produtiva do biodiesel como estratégia de desenvolvimento rural e política de distribuição de terras, na prática, foi marcada pela subordinação e sujeição destes agricultores às regas do agronegócio dos 
biocombustíveis. A produção em grande escala voltada para esse fim interferiu negativamente nos modos de vidas e reprodução social das famílias assentadas na condição de parceiros rurais da agroindústria do biodiesel.

\section{CONCLUSÕES}

Apesar dos avanços do PNPB, sobretudo, na região sul do Brasil, a meta de inclusão social dos agricultores pobres no estado do Piauí fracassou. A condição jurídica de parceria rural além de ter desencadeado uma série de conflitos sociais, também, alterou, significativamente, o modus operandi desses agricultores com a terra, produção e moradia.

A imposição de uma nova rotina de trabalho focada na produção em grande escala para atender aos negócios do biodiesel contribuiu para a estagnação da produção de mamona porque os agricultores não estavam habituados com aquele modelo de produção voltado, exclusivamente, para o mercado. É certo que, os agricultores parceiros desejavam produzir para comercializar, mas dentro da lógica de uma economia moral que valorizasse as suas próprias escolhas e não as do agronegócio.

Como resistência ao modelo de produção os agricultores abandonaram os tratos culturais da mamona, repercutindo diretamente na participação da empresa nos leilões do biodiesel. Deste modo, a proposta de assentamento público-privado não conseguiu atender nem a demanda de matéria prima para a produção de biodiesel, nem a distribuição de terras para fins de reforma agrária.

Por fim, é preciso refletir sobre os processos sociais decorrentes das atuais políticas públicas, particularmente as estaduais, que propõem promover a inclusão socioprodutiva e distribuição de terras em contextos de subordinação do agricultor assentado a modelos de projetos baseados em economia de mercado regido pelo capital agroindustrial. Desde o ano de 2015, o Estado vem negligenciando todas as demandas referentes ao cumprimento do contrato de parceria que previa a entrega da titularidade dos lotes medindo vinte e cinco hectares para as famílias que permanecessem, por no mínimo, dez anos no projeto do NPSC. Dez anos se passaram e as famílias não receberam a titularidade dos lotes e vivem a incerteza de continuarem ou partirem para novas rotas de migração por não terem condição de permanência nessas terras. Sem a titularização dessas terras, os agricultores estão excluídos do acesso a crédito rural e programas de a assistência técnica rural. A estabilidade do domínio da terra por intermédio da propriedade é fundamental para as famílias se sentirem seguras quanto a sua permanência nas terras do NPSC.

\section{REFERÊNCIAS}

BRANDÃO, C. R. Diário de campo: a antropologia como alegoria. São Paulo: Brasiliense, 1982. Plantar, colher, comer: um estudo sobre o campesinato goiano. Rio de Janeiro: Edições Graal, 1981.

BRAGA, Gustavo; FIÚZA, Ana Louise; REMOALDO, Paula Cristina. O conceito de modo de vida: entre traduções, definições e discussões. Sociologias, Porto Alegre, ano 19, no45, mai/ago 2017, p. 370-396.

BRASIL. Plano Nacional de Produção e Uso de Biodiesel. Ministério do Desenvolvimento Agrário MDA. Disponível em<www.inovaçãotecnologia.com.br>Acesso em 25 de Mar.2005.

BRASIL. Selo Combustível Social. Ministério do Desenvolvimento Agrário - MDA. Disponível em www.mda.gov.br. Acesso em 20 de janeiro de 2015. 
CANDIDO, Antônio. Parceiros do Rio Bonito: estudo sobre o caipira paulista e a transformação dos meios de vida. São Paulo, Ed. Duas cidades, 1987.

COMERFORD, John Cunha. Como uma família: sociabilidade de parentesco e sindicalismo rural. Rio de Janeiro: Relume Dumará: (coleção antropologia da política, 22), 2003.

DURHAM, Eunice Ribeiro. A Dinâmica da Cultura. São Paula, Ed. Cosacnaify, 2004.

FAO/INCRA. Perfil da Agricultura Familiar no Brasil: Dossiê estatístico. Brasília. Projeto UTF/BRA/036, 1996.

FOUCAULT, Michael. Vigiar e punir: história da violência nas prisões. Petrópolis, Ed. Vozes, 1987.

GASKELL. G. Entrevistas individuais e grupais. In: BAUER, M. W. e GASKELL, G. Pesquisa qualitativa com texto, imagem e som: um manual prático. Petrópolis-RJ: Vozes, 2002.

GOLDENBERG. M. A arte de pesquisar: como fazer pesquisa qualitativa em Ciências Sociais. 8. ed. Rio de Janeiro: Record, 2004.

PLOEG, Jan DouweVan der. Camponeses e a arte da agricultura: um manisfesto Chayanoviano. 1 ed. São Paulo; Porto Alegre: Editora Unesp; Editora UFRGS, 2016.

SCOTT, James. Los dominados y el arte de la resistência. México: Ed.Era, 2002.

SILVA, Erica Cristiane; LORETO, Maria das Dores Saraiva de: CALVELLI, Haudrey Germiniani. A dinâmica dos Polos de Produção de Biodiesel no contexto do PNPB. Revista Brasileira de Políticas Públicas. Vol.6, n.01. jul/dez, 2016.

SUAREZ, Mireya. Saber e reprodução camponesa. Anuário antropológico, Vol. 81, no. 2: 147 -229, 1983. 